\title{
Avaliação da qualidade de tomate seco em conserva
}

\author{
Gisele A. Camargo ${ }^{1}$, Niurka Haj-Isa ${ }^{2} \&$ Marlene R. de Queiroz $^{3}$
}

\section{RESUMO}

O tomate seco em conserva é alvo de crescente aceitação no mercado brasileiro; sua utilização é comum em aperitivos e na culinária como ingrediente de molhos e pizzas. Avaliou-se, neste trabalho o efeito dos seguintes fatores na qualidade do tomate seco: variedade de tomate (Rio Grande e Débora Plus), geometria de corte (pedaços de $1 \frac{1}{2}$ e $1 / 4$ com relação ao eixo maior do fruto), presença ou ausência de sementes e teor de umidade final (25 e 35\%), mediante análises instrumentais de cor e textura e testes sensoriais afetivos. Os resultados mostraram que a variedade Rio Grande apresentou melhor mastigabilidade e dureza, porém maior suscetibilidade ao escurecimento após o processo de secagem. De forma geral, a preferência dos consumidores foi por tomates secos com $35 \%$ de umidade final, enquanto a melhor qualidade final foi obtida a partir do tratamento com a variedade Rio Grande e umidade final de 35\%.

Palavras-chave: variedades, análise sensorial, parâmetros de qualidade

\section{Evaluation of quality of dried tomato}

\begin{abstract}
Preserved dried tomato has been gaining increasing acceptance in the Brazilian market, its use being common in appetizers and also in the cooking, as an ingredient of sauces and pizzas. The effect of the following factors on the quality of dried tomato was evaluated: variety of tomato (Rio Grande and Débora Plus), geometry of pieces ( $1 / 2$ and $1 / 4$ to the fruit major axis), presence or absence of seeds and final moisture content ( 25 and $35 \%$ ) by means of instrumental texture, and color analysis and sensorial affective tests. The results showed that the variety Rio Grande presented better physical parameters but was more susceptible to darkness. Generally, the consumers preferred dried tomatoes at $35 \%$ moisture content. The best final quality of dried tomato was obtained from the treatment performed with Rio Grande variety and 35\% final moisture content.
\end{abstract}

Key words: variety, sensorial analysis, quality parameters

1 Doutora em Tecnologia de Alimentos, Pesquisadora Científica, FRUTHOTEC/ITAL, Av. Brasil, 2880, CP 139, CEP 13070-170, Campinas, SP. Fone: (19) 3743-1840, Fax (19) 3242-3104. E-mail: camargo@ital.sp.gov.br

2 Doutora em Tecnologia de Alimentos, FESB/FAM/FAJ/CEUNSP, CP 183, CEP 12929-200, Bragança Paulista. Fone: (11) 4035-7800. E-mail: niurka_hajisa@hotmail.com

${ }_{3}^{3}$ FEAGRI/UNICAMP, CP 6011, Barão Geraldo, CEP 13083-875, Campinas. E-mail: marlene@agr.unicamp.br 


\section{INTRODUÇÃO}

Entre as hortaliças mundialmente cultivadas para consumo in natura e, sobretudo, industrializado, o tomate se sobressai, razão porque é considerado de produção e utilização universal. Segundo dados do Agrianual (2006), a área plantada com tomate no Brasil é superior a 58 mil hectares com produção anual em torno de 3,5 milhões de toneladas. Este fruto climatérico é altamente perecível e as técnicas de conservação na pós-colheita podem contribuir para minimizar suas perdas e lhe agregar valor.

A secagem de produtos com elevado teor de umidade inicial apresenta diversas vantagens tais como: inibição da ação de microrganismos, manutenção de constituintes minerais, redução de custos de transporte, manuseio e estocagem, tornando-se uma alternativa para a solução dos problemas de perda, descarte e poluição; além disso, no caso particular do tomate a secagem promove, entre outras, alteração do sabor e textura do fruto, conferindo-lhe paladar exótico, muito apreciado pelos consumidores.

O tomate seco foi introduzido no mercado brasileiro por imigrantes de países como Espanha e Itália e de algumas recentes produções domésticas nacionais. Em termos de pesquisa, vem-se observando nos últimos anos, interesse crescente pela qualidade deste produto. Estudos são desenvolvidos visando à investigação dos parâmetros de secagem e aplicação de novas tecnologias que minimizem os danos causados pelo calor à cor, textura, ao sabor e perda de nutrientes (Totobesola-Brabier et al., 2002; Veja et al., 2001; Camargo, 2003; Camargo et al., 2004; 2005).

Olorunda et al. (1990) estudaram a secagem de tomate em pedaços em secador com fluxo concorrente e contracorrente e avaliaram o efeito da temperatura de secagem (60, 70 e $80^{\circ} \mathrm{C}$ ) sob velocidade do ar de $1,75 \mathrm{~m} \mathrm{~s}^{-1}$, constatando que a taxa de secagem aumentou com a elevação da temperatura e a remoção de umidade foi maior no fluxo concorrente porém nada comentaram em relação aos efeitos dos parâmetros do processo na qualidade do produto final.

Romero et al. (1997) alertam para que a secagem do tomate seja realizada a temperaturas inferiores a $65^{\circ} \mathrm{C}$, visando à preservação da cor e sabor característicos, ainda que exija maior tempo de processo. Camargo \& Queiroz (1999) também observaram os efeitos negativos da temperatura de $80{ }^{\circ} \mathrm{C}$ na secagem de tomate, comparativamente à temperatura de $60^{\circ} \mathrm{C}$, ressaltando, como primeira causa, a queima superficial do produto. Os principais componentes da cor no tomate são o licopeno e o beta-caroteno (Gould, 1991).

A variedade do tomate, o estádio de amadurecimento e as reações químicas, estão intimamente ligados à firmeza e qualidade do produto após a secagem. Camargo (2000) reportou resultados de sólidos totais, acidez e sólidos solúveis para três variedades de tomate de mesa e duas de tomate industrial (inclusive as variedades Rio Grande e Débora Plus), comprovando que a porcentagem de sólidos no tomate varia em função da variedade.

Além de permitirem a criação de padrões de identidade para cada alimento, as medidas instrumentais auxiliam no processo de avaliação da sua qualidade em qualquer fase do processo produtivo, mas os mais avançados programas de computação, a adequação de métodos estatísticos e as técnicas gráficas têm sido incapazes de substituir a integração das percepções humanas ao consumir um produto in natura ou processado.

Nas atuais condições, com mercados multinacionais e mais competitivos, o sucesso de um produto depende não só dos aspectos de eficiência do processo e viabilidade econômica, mas, também, da satisfação ao sabor e expectativas do consumidor; portanto, considerar esses fatores é essencial no processo de desenvolvimento, otimização e melhoria da qualidade dos produtos e, para tanto, a análise sensorial se constitui em importante ferramenta.

A diversidade de métodos sensoriais divididos em dois grandes grupos (analíticos e afetivos), mostra um universo de possibilidades que se abrem para a avaliação de produtos em dissímeis áreas, incluindo a agroindústria.

O objetivo no presente trabalho foi avaliar a qualidade do tomate seco, abordada sob o enfoque das ferramentas de análises instrumentais e sensoriais.

\section{MATERIAL E MÉTODOS}

\section{Matéria-prima}

Tomates (Lycopersicon esculentum Mill) das variedades Débora Plus (de mesa) e Rio Grande (industrial), foram adquiridos junto ao CEASA/Campinas e ao CEAGESP/São Paulo, locais esses com maior disponibilidade. De acordo com a Associação Brasileira das Indústrias de Alimentos (ABIA, 1985), a matéria-prima apresentava características de frutos sadios, com coloração avermelhada, uniformes, sem pedúnculo, fisiologicamente desenvolvidos, limpos, com textura de polpa firme e avermelhada, livres de danos mecânicos, fisiológicos, pragas e doenças.

\section{Preparo das amostras}

No Laboratório, os frutos, acondicionados em caixas tipo “k”, foram mantidos a temperatura ambiente $\left(25 \pm 1^{\circ} \mathrm{C}\right)$ até que apresentassem cor adequada para a secagem, definida pela cor "vermelha” ou "molho", seguindo o padrão de cores da carta de comercialização do Programa Horti \& Fruti para padronização de produtos hortigranjeiros do Estado de São Paulo (CEAGESP, 1998).

Alcançada a cor desejada, realizou-se a sanitização dos frutos com água clorada (0,5\% de cloro ativo) para eliminar a contaminação por microrganismos (Moura et al., 1998); posteriormente, os tomates foram selecionados por tamanho, para uniformização prévia ao processo de secagem, com base no calibre médio para formato redondo dos frutos da variedade de mesa Débora Plus, cujo diâmetro varia de 65 a 70 mm (CEAGESP, 1998). Seguindo a mesma norma para a variedade industrial Rio Grande, o diâmetro transversal correspondeu ao tamanho médio do formato oblongo, o qual se encontra no intervalo de 50 a $60 \mathrm{~mm}$; a medida dos diâmetros foi feita com um paquímetro digital com escala de 0 a $150 \mathrm{~mm}$ e precisão de $0,01 \mathrm{~mm}$. 
Considerando-se o tomate seco imerso em azeite comumente encontrado no mercado, os frutos foram cortados em pedaços correspondentes à metade e um quarto do tomate segundo o eixo maior. $\mathrm{O}$ corte foi realizado manualmente, com faca afiada; por sua vez, a retirada da semente das amostras assim tratadas, foi feita manualmente, com auxílio de uma faca e uma colher, procurando-se não afetar a polpa do fruto; por fim, a secagem foi conduzida em secador convectivo com controle de temperatura $\left(60^{\circ} \mathrm{C}\right)$ e velocidade do ar $\left(0,55 \mathrm{~m} \mathrm{~s}^{-1}\right)$, distribuindo-se os pedaços em bandejas com fundo de tela $(1 \times 1 \mathrm{~cm})$.

Após atingirem o teor de umidade desejado (25 ou 35\%) as amostras, resfriadas a temperatura ambiente, foram embaladas em sacos de polietileno fechados, com capacidade de 200 g e mantidas em geladeira, até o preparo final com vistas à realização dos testes instrumentais e afetivos.

O preparo final compreendeu a imersão das amostras em azeite de oliva e sal, na proporção de $50 \mathrm{~g}$ de tomate seco por $100 \mathrm{~mL}$ de azeite e $3 \%$ de sal com relação ao peso das amostras; foram mantidas nesta condição durante $48 \mathrm{~h}$ e, posteriormente, submetidas às avaliações físicas e sensoriais.

\section{Tratamentos realizados}

O planejamento experimental baseou-se em delineamento fatorial $2^{4}$ visando avaliar os efeitos dos seguintes parâmetros na qualidade do produto final: variedade (Rio Grande e Debora Plus), geometria de corte (pedaços de 1/2 e $1 / 4$ com relação ao eixo maior do fruto), presença ou ausência de sementes e teor de umidade final (25 e 35\%), resultando em 16 tratamentos experimentais (Tabela 1).

Tabela 1. Tratamentos realizados para avaliação da qualidade do tomate seco

\begin{tabular}{ccccc}
\hline Tratamentos & Variedade & Corte & $\begin{array}{c}\text { Presença de } \\
\text { semente }\end{array}$ & $\begin{array}{c}\text { Umidade final } \\
(\%)\end{array}$ \\
\hline 1 & $\mathrm{DP}(1)$ & $1 / 2$ & Sim & 25 \\
2 & $\mathrm{DP}$ & $1 / 2$ & Sim & 35 \\
3 & $\mathrm{DP}$ & $1 / 2$ & Não & 25 \\
4 & $\mathrm{DP}$ & $1 / 2$ & Não & 35 \\
\hline 5 & $\mathrm{DP}$ & $1 / 4$ & Sim & 25 \\
6 & $\mathrm{DP}$ & $1 / 4$ & Sim & 35 \\
\hline 7 & $\mathrm{DP}$ & $1 / 4$ & Não & 25 \\
8 & $\mathrm{DP}$ & $1 / 4$ & Não & 35 \\
\hline & $\mathrm{RG}(2)$ & $1 / 2$ & Sim & 25 \\
10 & $\mathrm{RG}$ & $1 / 2$ & Sim & 35 \\
\hline 11 & $\mathrm{RG}$ & $1 / 2$ & Não & 25 \\
12 & $\mathrm{RG}$ & $1 / 2$ & Não & 35 \\
\hline 13 & $\mathrm{RG}$ & $1 / 4$ & Sim & 25 \\
14 & $\mathrm{RG}$ & $1 / 4$ & Sim & 35 \\
15 & $\mathrm{RG}$ & $1 / 4$ & Não & 25 \\
16 & $\mathrm{RG}$ & $1 / 4$ & Não & 35 \\
\hline
\end{tabular}

(1) Débora Plus, (2) Rio Grande

\section{Avaliações físicas}

A variável dependente cor do produto final foi determinada em espectrofotômetro Color Quest II - Hunter Lab. O sistema de leitura utilizado foi CIELAB iluminante D-65, com ângulo de observação constante de $10^{\circ}$. Realizaram-se três repetições por tratamento.

A textura das amostras em função das propriedades dureza, mastigabilidade, adesividade e gomosidade, foi mensurada em texturômetro Stable Micro Systems, modelo TA-XT2i, equipado com "probe" cilíndrico, diâmetro 1 cm, ao qual se aplicou uma força de compressão constante e unidirecional, com distância de compressão de 2,0 mm e intervalo de tempo de $0,5 \mathrm{~s}$ entre duas compressões como simulação de duas mastigadas; as medidas foram tomadas no ponto central de cada pedaço de tomate seco ( $1 / 2$ e $1 / 4$ conforme tratamento); três repetições para cada tratamento e um único pedaço em cada repetição.

Os resultados de cor e textura foram submetidos à análise de variância (ANOVA), Teste de Tukey e análise de superfície de resposta, utilizando-se o software Statistica ${ }^{\circledR}$ 6.0.

\section{Avaliação sensorial}

O delineamento experimental aplicado neste trabalho gerou grande número de tratamentos (Tabela 1), exigindo que a análise fosse conduzida em duas etapas.

Inicialmente, buscou-se identificar se a aparência geral do produto final poderia ser determinante na preferência do consumidor, para tanto se aplicou um teste afetivo considerando-se os atributos cor, tamanho, textura visual e aparência geral.

Uma equipe de 35 provadores não treinados e consumidores do produto avaliou as amostras através de escala hedônica mista estruturada de 5 pontos ( 1 = desgostei muito, 5 = gostei muito); essas amostras foram apresentadas monadicamente, seguindo-se delineamento de blocos completos casualizados e os dados obtidos foram submetidos a ANOVA com fator duplo (amostra e provador) para verificar diferença entre os tratamentos e ao teste de Tukey (5\%) para comparação de médias.

Os resultados desta etapa permitiram a seleção dos quatro melhores tratamentos, conforme critério baseado nas maiores notas atribuídas à aparência geral. Submeteram-se os tratamentos selecionados aos testes de aceitação e intenção de compra (Tabela 2), realizados por uma equipe constituída de 37 consumidores não treinados, por apreciadores de tomate seco temperado em óleo; as amostras foram avaliadas monadicamente.

Os resultados do teste de aceitação foram avaliados mediante análise de variância e teste de comparação de médias (Tukey 5\%), utilizando-se o software Statistica ${ }^{\circledR}$ 6.0.

Ambos os testes sensoriais foram realizados em cabinas individuais climatizadas a temperatura aproximada de $22{ }^{\circ} \mathrm{C}$ e as amostras dispostas em pratos brancos, sob luz fluorescente.

\section{RESULTADOS E DISCUSSÃO}

\section{Medida instrumental de cor}

Dentre os componentes da cor, apenas a luminosidade (L) apresentou diferença significativa $(p=0,0279)$ e somente em 
Tabela 2. Ficha utilizada no teste de aceitação e intenção de compra de tomate seco temperado

Nome:

Data:

1. Por favor, PROVE a amostra e indique, utilizando a escala abaixo, o quanto você dela gostou ou desgostou:
9 gostei extremamente
8 gostei muito
7 gostei moderadamente
6 gostei ligeiramente
5 não gostei/nem desgostei
4 desgostei ligeiramente
3 desgostei moderadamente
2 desgostei muito
1 desgostei extremamente

2. Descreva, por favor, o de que você mais gostou e de que menos gostou na amostra, EM TERMOS GLOBAIS.

Mais gostei:

Menos gostei:

3. Finalmente, indique, utilizando a escala abaixo, qual sua atitude se você encontrasse esta amostra à venda.

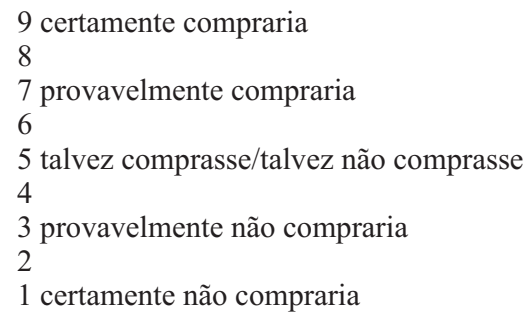

Comentários:

relação à variedade do tomate, sem que os fatores geometria de corte, presença de sementes e teor de umidade final incidissem sobre este parâmetro; a variedade Rio Grande apresentou menores valores (média de $L=7,5$ ) o que pode ser interpretado como suscetibilidade maior ao escurecimento desta variedade, quando submetida ao processo de secagem, comparativamente à variedade Débora Plus.

\section{Medida instrumental de textura}

A variável resposta mastigabilidade apresentou diferença significativa para os fatores variedade $(\mathrm{p}=0,0288)$ e semente ( $p=0,0461)$, conforme se observa na Tabela 3 . Ressalta-se que para o tomate seco a melhor mastigabilidade (valor maior) encontrada foi da variedade Rio Grande (Figura 1).

Tabela 3. Análise de variância para propriedade mastigabilidade das amostras de tomate seco

\begin{tabular}{ccc}
\hline Variáveis independentes & \multicolumn{2}{c}{ Mastigabilidade } \\
\cline { 2 - 3 } Variedade (1) & $\mathbf{F}$ & $\mathbf{p}^{*}$ \\
Corte (2) & 9,2277 & 0,0288 \\
Semente (3) & 2,2082 & 0,1974 \\
Umidade (4) & 6,9534 & 0,0461 \\
$1 \times 2$ & 2,0631 & 0,2104 \\
$1 \times 3$ & 1,0035 & 0,3625 \\
$1 \times 4$ & 5,3320 & 0,0690 \\
$2 \times 3$ & 1,9023 & 0,2263 \\
$2 \times 4$ & 3,2297 & 0,1322 \\
$3 \times 4$ & 0,4377 & 0,5375 \\
\hline
\end{tabular}

*Valores de $p<0,05$, indicam efeito estatisticamente significativo das variáveis avaliadas

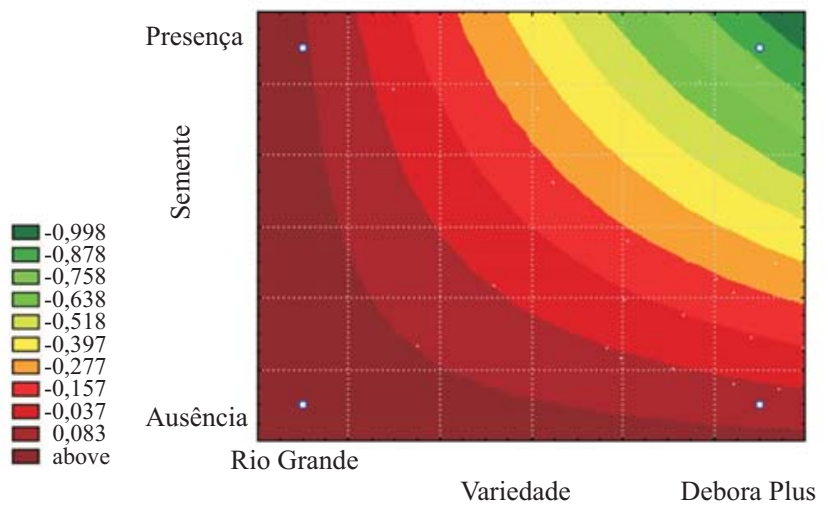

Figura 1. Superfície de resposta obtida na avaliação da mastigabilidade das amostras de tomate seco

A presença de sementes exerceu efeito significativo na mastigabilidade somente nos tomates da variedade Débora Plus, a qual apresentou valores menores deste atributo nos tratamentos que continham sementes, o que pode ser entendido como maior dificuldade no processo de mastigação (Figura 1).

A inobservância do efeito da presença de sementes sobre a mastigabilidade na variedade Rio Grande (Figura 1) pode ser atribuída à pequena quantidade de sementes nesta variedade.

Os resultados estimados da incidência das variáveis independentes e suas interações sobre a variável resposta dureza, também indicam o efeito da variedade neste atributo do tomate seco, isto é, mudanças na variedade do tomate in natura produziram variações importantes nos valores de dureza do tomate seco em conserva (Figura 2).

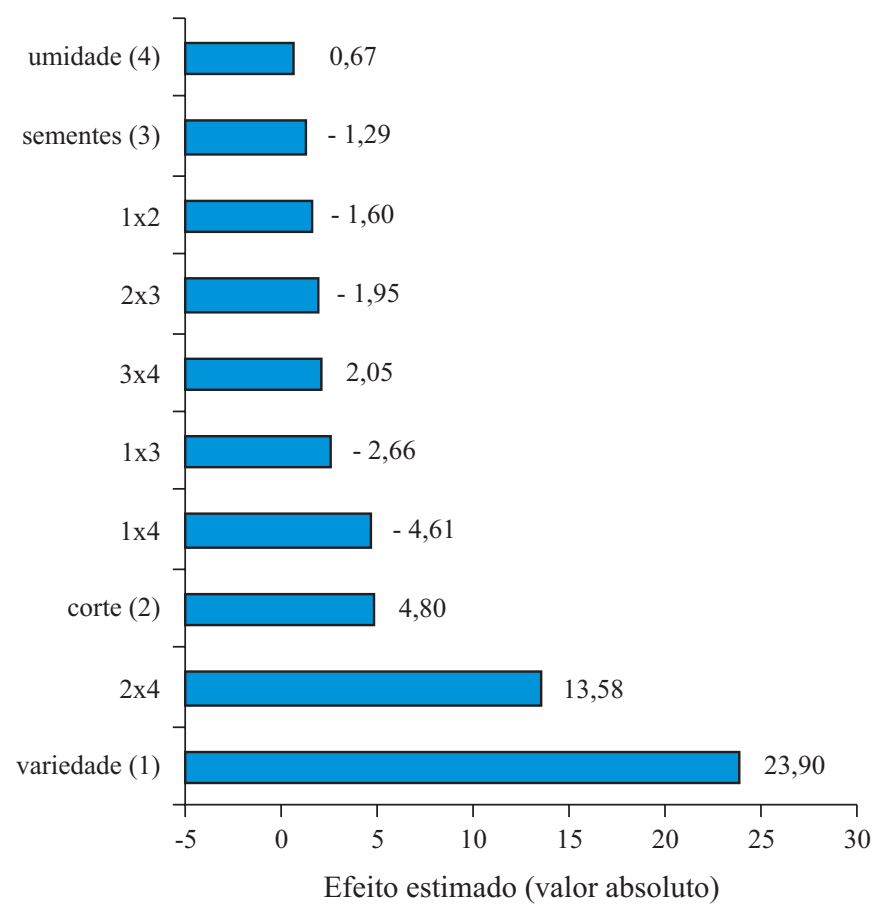

Figura 2. Efeito das variáveis respostas e suas interações sobre a dureza das amostras de tomate seco. 
A variedade Débora Plus apresentou maior dureza, significativamente diferente da variedade Rio Grande (Figura 3).

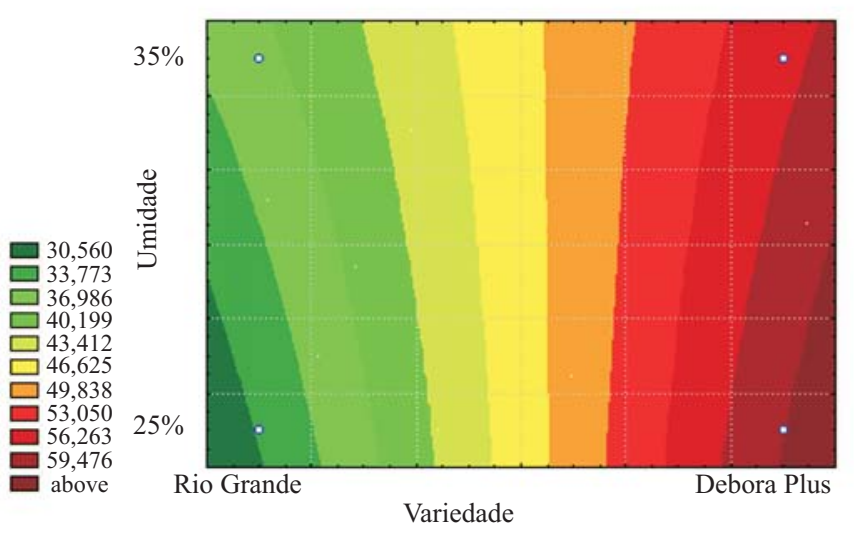

Figura 3. Superfície de resposta obtida na avaliação da dureza de tomate seco

\section{Avaliação sensorial da aparência}

Os resultados do teste afetivo de aparência sensorial permitiram a seleção de quatro tratamentos (Tabela 4), com base nas maiores médias de “aparência geral”. Acrescenta-se ainda que os quatro tratamentos selecionados não diferiram estatisticamente entre si $(p<0,05)$ em relação aos demais atributos avaliados.

Tabela 4. Descrição dos tratamentos selecionados no teste sensorial de aparência avaliados em escala hedônica de 5 pontos

\begin{tabular}{cccccc}
\hline & \multicolumn{5}{c}{ Notas por atributos } \\
\cline { 2 - 6 } Tratamento & $\begin{array}{c}\text { Aparência } \\
\text { geral }\end{array}$ & Cor & Tamanho & $\begin{array}{c}\text { Textura } \\
\text { visual }\end{array}$ \\
\hline $\begin{array}{l}\text { Variedade Debora Plus, corte ao meio, } \\
\text { sem semente, umidade final de 35\% }\end{array}$ & 3,3 & 3,9 & 3,5 & 3,3 \\
$\begin{array}{l}\text { Variedade Debora Plus, corte em } \\
\text { quatro partes, sem semente, } \\
\text { umidade final de 25\% }\end{array}$ & 3,6 & 4,0 & 3,3 & 3,3 \\
\hline $\begin{array}{l}\text { Variedade Rio Grande, corte ao meio, } \\
\text { com semente, umidade final de 35\% } \\
\text { Variedade Rio Grande, corte em }\end{array}$ & 3,7 & 3,9 & 3,9 & 3,5 \\
\hline $\begin{array}{l}\text { quatro partes, sem semente, } \\
\text { umidade final de 35\% }\end{array}$ & 3,5 & 3,8 & 3,2 & 3,7 \\
\hline
\end{tabular}

As amostras dos demais tratamentos foram rejeitadas visto que apresentaram, em algum dos atributos, notas iguais, inferiores ou muito próximas ao limite de aceitação $(3,0)$, conforme a escala de avaliação utilizada.

\section{Testes de aceitação e intenção de compra}

Nenhum dos tratamentos selecionados apresentou nota média abaixo de 5,0 (limite inferior de aceitação), conforme a escala hedônica de 9 pontos utilizada nos testes de aceitação e intenção de compra (Tabela 5), o que permite afirmar que os produtos apresentam características sensorialmente adequadas para comercialização; no entanto, houve diferenças estatisticamente significativa $(\mathrm{p}<0,05)$ entre os tratamentos, em ambos os testes.

O tratamento 2 apresentou a menor média na aceitação, diferindo das outras amostras $(\mathrm{p}<0,05)$ significando que os provadores gostaram mais das amostras com maior teor de umidade final, provavelmente, por serem mais macias, constatação esta confirmada com a opinião dos juízes, quando perguntados sobre o que mais gostaram/desgostaram nas amostras. Aproximadamente $50 \%$ dos provadores criticaram o tratamento com $25 \%$ de umidade e apontaram a "textura dura” como a característica de que menos gostaram.

Tabela 5. Resultados do teste afetivo de aceitação e intenção de compra avaliados com escala hedônica de 9 pontos

\begin{tabular}{lcc}
\hline \multicolumn{1}{c}{ Tratamento } & Aceitação* & $\begin{array}{c}\text { Intenção de } \\
\text { Compra* }\end{array}$ \\
\hline $1 \begin{array}{l}\text { Variedade Debora Plus, corte ao meio, sem } \\
\text { semente, umidade final de 35\% }\end{array}$ & $6,6 \mathrm{a}$ & $5,5 \mathrm{~b}$ \\
\hline $\begin{array}{l}\text { Variedade Debora Plus, corte em quatro } \\
\text { partes, sem semente, umidade final de 25\% }\end{array}$ & $5,3 \mathrm{~b}$ & $4,3 \mathrm{~b}$ \\
\hline $\begin{array}{l}\text { Variedade Rio Grande, corte ao meio, com } \\
\text { semente, umidade final de 35\% }\end{array}$ & $6,4 \mathrm{a}$ & $5,9 \mathrm{a}$ \\
\hline $\begin{array}{l}\text { Variedade Rio Grande, corte em quatro } \\
\text { partes, sem semente, umidade final de 35\% }\end{array}$ & $6,3 \mathrm{a}$ & $5,2 \mathrm{~b}$ \\
\hline${ }^{*}$ Médias seguidas de letras iguais na vertical não diferem entre si pelo teste de Tukey (5\%)
\end{tabular}

Nota-se, ainda, que a presença de sementes na variedade Rio Grande não alterou a nota média da aceitação dos julgadores, cujo resultado indica que a pequena quantidade de sementes nesta variedade impede a percepção do efeito pelo consumidor ou que a presença de sementes não é considerada fator importante na aceitação das amostras; na análise da medida instrumental de mastigabilidade da variedade Rio Grande também não se observou efeito da presença de sementes.

Nas amostras que receberam as médias mais altas de aceitação, a característica "sabor geral" foi a mais apreciada e mencionada com maior freqüência para os tratamentos da variedade Rio Grande.

Os resultados indicados na Figura 4 sugerem que os tratamentos 1 e 3 seriam os produtos mais comprados os quais têm, em comum, a geometria de corte e a umidade final de 35\%.

Embora os tratamentos 1 e 3 tenham a mesma aceitação

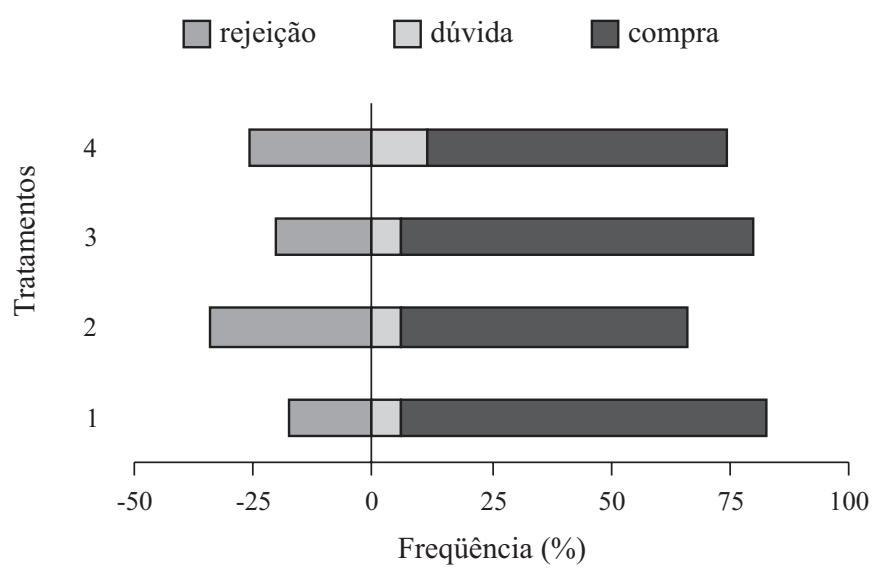

Figura 4. Freqüência das notas obtidas no teste de intenção de compra de tomate seco sob diferentes tratamentos. Rejeição (soma das notas 1 a 4); dúvida (nota 5); aceitação (soma das notas 6 a 9) 
por parte dos consumidores, de acordo com os resultados da ANOVA e Tukey, o tomate seco da variedade Rio Grande, corte ao meio, com semente e umidade final de 35\% (Tabela 5) diferiu estatisticamente ( $p<0,05)$ dos demais tratamentos, obtendo a maior média de intenção de compra.

\section{Cruzamento de dados instrumentais e sensoriais}

A correlação entre as variáveis que mostraram comportamento estatisticamente significativo $(p<0,05)$ revela que tanto a aceitação quanto a intenção de compra serão maiores quanto menor for a dureza e maior a mastigabilidade, esta última incidindo mais na aceitação que na compra do produto (Tabela 6).

Tabela 6. Correlação (r) entre dados instrumentais e sensoriais avaliados em tomate seco temperado

\begin{tabular}{lcccc}
\hline Parâmetros & $\begin{array}{c}\text { Intenção de } \\
\text { compra }\end{array}$ & $\begin{array}{c}\text { Luminosidade } \\
\text { (L) }\end{array}$ & Dureza & Mastigabilidade \\
Aceitação & 0,9081 & 0,198 & $-0,92$ & 0,7175 \\
Intenção de compra & & $-0,17$ & $-0,98$ & 0,4827 \\
\hline
\end{tabular}

\section{CONCLUSÕES}

1. A cor do tomate seco não foi influenciada pela geometria de corte, teor de umidade, presença ou ausência de sementes, sendo que o valor de $\mathrm{L}$ o foi pela variedade.

2. A variedade Rio Grande apresentou melhor mastigabilidade e dureza, também maior suscetibilidade ao escurecimento após o processo de secagem.

3. A preferência dos consumidores foi por tomates secos com 35\% de umidade final.

4. A melhor qualidade final do tomate seco foi obtida no tratamento realizado com a variedade Rio Grande e umidade final de $35 \%$.

5. A mastigabilidade apresentou efeito direto na aceitação do consumidor.

\section{AGRADECIMENTO}

À FAPESP, pela concessão de bolsa de mestrado e reserva técnica.

\section{LITERATURA CITADA}

Agrianual 2005. Anuário da Agricultura Brasileira. São Paulo: FNP Consultoria e Comércio, 2006. 532p.
ABIA - Associação Brasileira das Indústrias de Alimentação. Comissão Nacional da Legislação de Alimentos: Consolidação das normas e padrões de alimentos. Resolução 12/78 (12/7 Frutas secas ou dessecadas). São Paulo. v.1/A, p.7.5(78), 1985.

Camargo, G. A. Secagem de tomate (Lycopersicon esculentum Mill) para conserva: Estudo de parâmetros com base na qualidade final. Campinas: UNICAMP, 2000. 74p. Dissertação Mestrado

Camargo, G. A. Processo produtivo de tomate seco: novas tecnologias - Manual Técnico. Tomate na UNICAMP. http:// www.agr.unicamp.br. 10 Ago. 2003.

Camargo, G. A. Novas tecnologias e pré-tratamentos: tomate seco embalado a vácuo. Campinas: UNICAMP, 2005. 162p. Tese Doutorado

Camargo, G. A.; Moretti, R. H.; Ledo, C. A. S . Quality of dried tomato pre-treated by osmotic dehydration, antioxidant application and addition of tomato concentrate. In: International Drying Symposium, 14, 2004, São Paulo. Proceedings... Campinas: UNICAMP, 2004. p.2207.

Camargo, G. A.; Queiroz, M. R. Curvas experimentais de secagem de tomate, variedade Debora Plus, em duas temperaturas e pré-tratamento com sal e açúcar. In: Congresso Brasileiro de Engenharia Agrícola, 28, 1999, Pelotas. Anais... Pelotas: SBEA, 1999. 3p.

CEAGESP - Companhia de Entrepostos e Armazéns Gerais de São Paulo. Programa Horti \& Fruti Padrão - Classificação do tomate. Câmara Setorial de Hortaliças do Estado de São Paulo. 1998. http://www.cati.sp.gov.br/novacati/index.php. 12 Abr. 2005.

Gould, W. A. Composition of tomatoes. In: Gould, W. A. (ed.). Tomato production, processing and quality evaluation. Connectitut: AVI Publishing Co., 1991. cap.2, p.344-358.

Moura, M. A.; Zanin, S. R.; Finger, F. L. Amadurecimento de tomate com pulverização de diferentes doses de Ethephon associado com espalhante adesivo. Revista Brasileira de Armazenamento, Viçosa, v.23, p.11-14, 1998.

Olorunda, A.; Aworh, C.; Onuoha, C. M. Upgrading quality of dried tomato: effects of drying methods, conditions and pre-drying treatments. Journal of Science of Food and Agriculture, Nova York, v.52, p.447-454, 1990.

Romero, L. M.; Miguel, M. H.; Spogis, N.; Kieckbusch, T. G. Cinética de secagem de tomates em fatias pré-tratadas: Resultados preliminares. In: Congresso Brasileiro de Sistemas Particulados, 25, 1997, São Carlos. Anais... São Carlos: SBEQ, 1997. p.627.

Totobesola-Barbier, M.; Marouzé, C.; Giroux, F. A Triz - based creativity tool for food processing equipment design. The TRIZ Journal Article Archives, Out, 2002. http://www.trizjournal.com/archives. 3 Ago. 2006.

Veja, M.; Góngora, N.; Barbosa, C. Advances in dehydration of foods. Journal of Food Engineering, Amsterdam, v.49, p.271289, 2001. 